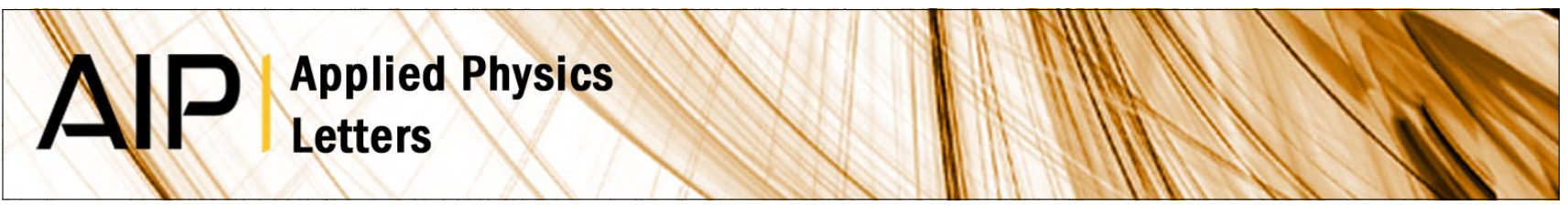

\title{
Highly efficient potentiometric glucose biosensor based on functionalized InN quantum dots
}

N. H. Alvi, P. E. D. Soto Rodriguez, V. J. Gómez, Praveen Kumar, G. Amin et al.

Citation: Appl. Phys. Lett. 101, 153110 (2012); doi: 10.1063/1.4758701

View online: http://dx.doi.org/10.1063/1.4758701

View Table of Contents: http://apl.aip.org/resource/1/APPLAB/v101/i15

Published by the American Institute of Physics.

\section{Related Articles}

Comparative evaluation of ultrasound scanner accuracy in distance measurement Rev. Sci. Instrum. 83, 105103 (2012)

Deterministic separation of cancer cells from blood at $10 \mathrm{~mL} / \mathrm{min}$ AIP Advances 2, 042107 (2012)

Development of miniaturized, portable magnetic resonance relaxometry system for point-of-care medical diagnosis

Rev. Sci. Instrum. 83, 095115 (2012)

Rapid detection of live methicillin-resistant Staphylococcus aureus by using an integrated microfluidic system capable of ethidium monoazide pre-treatment and molecular diagnosis

Biomicrofluidics 6, 034119 (2012)

A compact instrument for adjusting laser beams to be accurately coincident and coaxial and its use in biomedical imaging using wave-mixed laser sources

Rev. Sci. Instrum. 83, 083705 (2012)

\section{Additional information on Appl. Phys. Lett.}

Journal Homepage: http://apl.aip.org/

Journal Information: http://apl.aip.org/about/about_the_journal

Top downloads: http://apl.aip.org/features/most_downloaded

Information for Authors: http://apl.aip.org/authors

\section{ADVERTISEMENT}

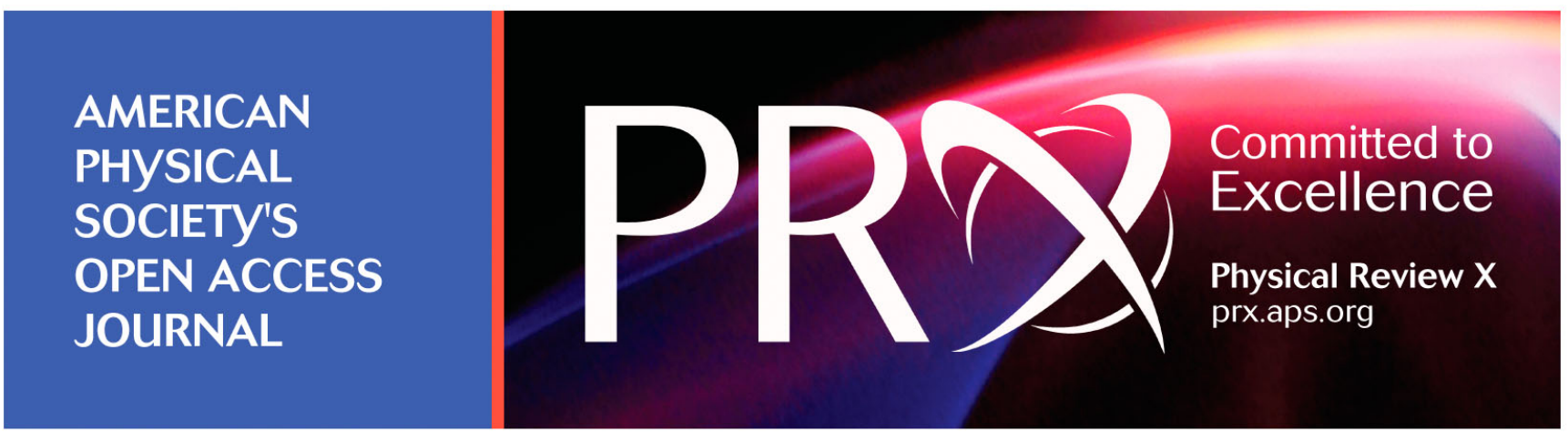




\title{
Highly efficient potentiometric glucose biosensor based on functionalized InN quantum dots
}

\author{
N. H. Alvi, ${ }^{1, a)}$ P. E. D. Soto Rodriguez, ${ }^{1}$ V. J. Gómez, ${ }^{1}$ Praveen Kumar, ${ }^{1}$ G. Amin, ${ }^{2}$ O. Nur, ${ }^{2}$ \\ M. Willander, ${ }^{2}$ and R. Nötzel ${ }^{1, a)}$ \\ ${ }^{1}$ Institute for Systems Based on Optoelectronics and Microtechnology (ISOM), \\ Ciudad Universitaria s/n 28040 Universidad Politécnica de Madrid, Spain \\ ${ }^{2}$ Department of Science and Technology (ITN), Campus Norrkoping, Linköping University, 60174 Norrköping, \\ Sweden
}

(Received 26 August 2012; accepted 28 September 2012; published online 9 October 2012)

\begin{abstract}
We present a fast, highly sensitive, and efficient potentiometric glucose biosensor based on functionalized InN quantum-dots (QDs). The InN QDs are grown by molecular beam epitaxy. The InN QDs are bio-chemically functionalized through physical adsorption of glucose oxidase (GOD). GOD enzyme-coated InN QDs based biosensor exhibits excellent linear glucose concentration dependent electrochemical response against an $\mathrm{Ag} / \mathrm{AgCl}$ reference electrode over a wide logarithmic glucose concentration range $\left(1 \times 10^{-5} \mathrm{M}\right.$ to $\left.1 \times 10^{-2} \mathrm{M}\right)$ with a high sensitivity of $80 \mathrm{mV} / \mathrm{decade}$. It exhibits a fast response time of less than $2 \mathrm{~s}$ with good stability and reusability and shows negligible response to common interferents such as ascorbic acid and uric acid. The fabricated biosensor has full potential to be an attractive candidate for blood sugar concentration detection in clinical diagnoses. (C) 2012 American Institute of Physics. [http://dx.doi.org/10.1063/1.4758701]
\end{abstract}

III-V semiconductor materials have promising applications in electronic and optoelectronic devices. Indium nitride ( $\mathrm{InN}$ ) has engrossed a lot of attention in the development of electronic and photonic devices due to recent progress in the growth of InN based nanostructures. The growth of $\mathrm{InN}$ nanostructures by molecular beam epitaxy (MBE) paved the way to investigate their unusual optical and electrical properties. $^{1-5}$ It has been investigated and confirmed by many research reports that undoped, as-grown $\mathrm{InN}$ nanostructures contain an intrinsic electron accumulation at the surface which is very unusual among III-V semiconductors. Efforts to eliminate the surface electron accumulation by chemical or physical treatments have not yet been successful. It has been reported that the positively charged donor surface state density of InN nanostructures is as high as $10^{13} \mathrm{~cm}^{-2}$ which causes the highest native electron accumulation observed in III-V semiconductor nanostructures. ${ }^{6-11}$

Due to the high surface charge density and robust surface properties, InN nanostructures are very attractive candidates for sensing applications. Indeed, InN has been proposed to be useful for sensing applications. ${ }^{11-15}$ The development of biosensors based on InN QDs is potentially very interesting taking advantage of their low dimensionality, high surface to volume ratio, and largest native surface electron accumulation, being dominating parameters for biosensing. Moreover, the planar arrangement of the epitaxial InN QDs promises rapid signal response. The high density of positively charged surface donor states of InN should allow negatively charged ions in solution to be selectively attracted to the InN surface. This is the base of the sensor principle to determine the glucose concentration by measuring the potential difference between the electrically contacted InN QDs

\footnotetext{
a) Authors to whom correspondence should be addressed. Electronic addresses: nhalvi@isom.upm.es and r.noetzel@isom.upm.es. Tel.: +34 915495700 ext. 8065 .
}

and a $\mathrm{Ag} / \mathrm{AgCl}$ reference electrode. This potential difference is produced by the change of surface charge density of the InN QDs due to the redox reaction with $\mathrm{H}_{2} \mathrm{O}_{2}$ which is generated by the reaction between glucose and glucose oxidase in the electrolyte solution. ${ }^{16}$

There are many techniques for the sensing of biomolecules, and among them the enzymatic electrochemical biosensing technique is an important alternative to other nonenzymatic biosensing techniques as it requires only a simple experimental setup, short execution of the experiments, and cheap chemicals. The enzymatic biosensors are fabricated by immobilization of different types of enzymes onto the surface of the biocompatible sensing material, which are selected according to the target molecules. Glucose oxidase (GOD) is the most commonly employed enzyme in glucose biosensors because of its high selectivity to glucose molecules.

In our life, the controlled level of glucose concentration in the blood is a crucial parameter for the prevalence of many major life threatening diseases. This strongly motivates the fabrication of robust, simple, cheap, and non-invasive glucose biosensors with high sensitivity, good selectivity, fast and stable response, and high thermal stability. Here we present a glucose biosensor based on InN QDs functionalized through immobilization of glucose oxidase onto the surface. The fabricated glucose biosensor exhibits fast and stable output response along with good linear sensitivity over a wide logarithmic glucose concentration range from $1 \times 10^{-5} \mathrm{M}$ to $1 \times 10^{-2} \mathrm{M}$ which easily covers the range of glucose concentration in human blood. ${ }^{17}$ Additionally, the presented biosensor not only reveals a rapid response time but also demonstrates good selectivity and repeatability at room temperature. It also exhibits good reusability, altogether revealing full potential to be used for practical applications.

The chemicals used were GOD type GO3A from Aspergillus niger, $360 \mathrm{U} / \mathrm{mg}$ (BBI Enzymes (UK) Ltd.) and Nafion (5 wt. \%), glutaraldehyde (50\% solution), Bovine serum 
albumin (BSA $\geq 98 \%$ ), and $\mathrm{d}-(+)$-glucose (99.5\%) from Sigma-Aldrich. A phosphate buffered, $10 \mathrm{mM}$ solution (PBS) from $\mathrm{Na}_{2} \mathrm{HPO}_{4}$ and $\mathrm{KH}_{2} \mathrm{PO}_{4}$ (Sigma-Aldrich) was prepared with sodium chloride having concentration of $0.134 \mathrm{mM}$. The $p \mathrm{H}$ value of the PBS solution was adjusted to 7.4.

For biosensor fabrication, first a GOD stock solution was prepared. $10 \mathrm{mg} / \mathrm{ml}$ GOD was dissolved in PBS with $p \mathrm{H}$ value of 7.4 and kept stirring for $24 \mathrm{~h}$. The InN QDs sample was dipped in a $5 \mathrm{ml}$ enzyme solution (GOD) for $20 \mathrm{~min}$ at room temperature for surface functionalization and dried in air for $2 \mathrm{~h}$. To prevent possible enzyme leakage and eliminate foreign interferences a $3 \mu \mathrm{l}$ aqueous solution of $2.5 \%$ glutaraldehyde and $0.5 \%$ Nafion was applied onto the electrodes surface. All glucose biosensors were stored at $4{ }^{\circ} \mathrm{C}$ in dry condition when not in use. The electrochemical measurements were performed in glucose solutions with concentrations ranging from $10 \mu \mathrm{M}$ to $100 \mathrm{mM}$ versus an $\mathrm{Ag} / \mathrm{AgCl}$ reference electrode from Metrohm $(3 \mathrm{MKCl})$ and recorded by a computer controlled Keithley 2400 source meter.

Figure 1(a) shows the atomic force microscopy (AFM) image of 2 monolayers InN QDs grown on a $80 \mathrm{~nm}$ thick $\mathrm{In}_{0.54} \mathrm{Ga}_{0.46} \mathrm{~N}$ layer on a $(0001) \mathrm{GaN} /$ sapphire substrate by plasma assisted molecular beam epitaxy (PA-MBE). The AFM image of the bare InGaN layer is shown in Fig. 1(b). Details of the growth will be presented elsewhere. The QDs exhibit an average height of $4 \mathrm{~nm}$, mean diameter of $35 \mathrm{~nm}$, and density of $4.5 \times 10^{10} \mathrm{~cm}^{-2}$, and the InGaN layer has a smoothly modulated surface. Figures 1(c) and 1(d) depict the I-V curves measured with two Al contacts, half a millimeter apart, deposited on the InN QDs and bare InGaN layers, respectively, showing excellent ohmic behavior with low resistance. This is due to the high n-type conductivity commonly established in high In composition (>50\%) InGaN layers. Figure 2 depicts the schematic illustration of the glucose sensing setup using the working electrode comprised of functionalized $\mathrm{InN}$ QDs against a $\mathrm{Ag} / \mathrm{AgCl}$ reference elec-

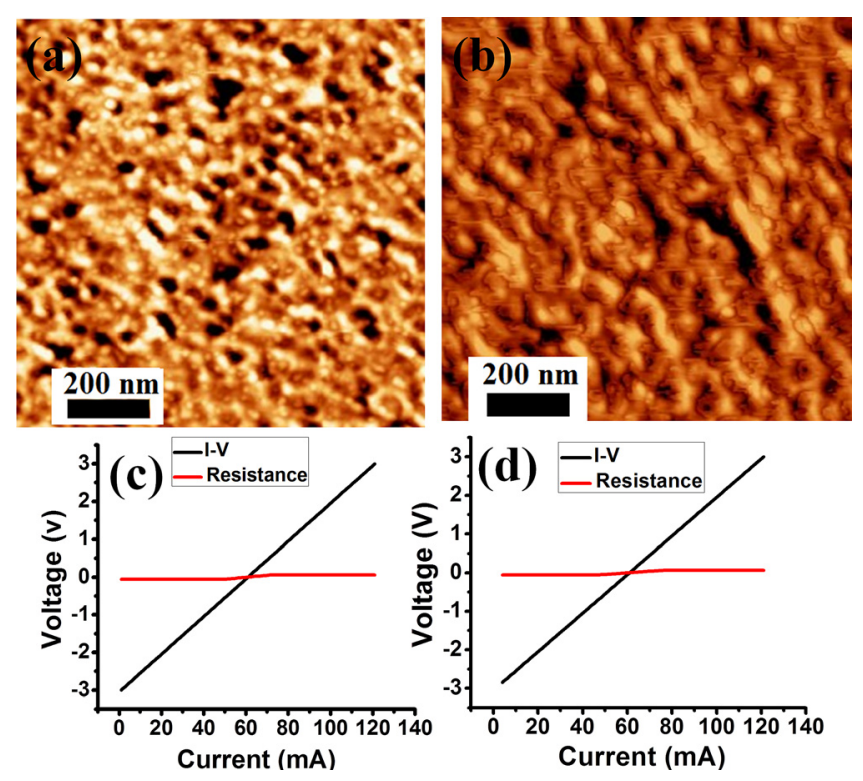

FIG. 1. (a) AFM image of InN QDs grown on InGaN layer. (b) AFM image of InGaN layer grown on GaN. (c), (d) I-V curves measured with two Al ohmic contacts deposited on InN QDs and InGaN layer, respectively.

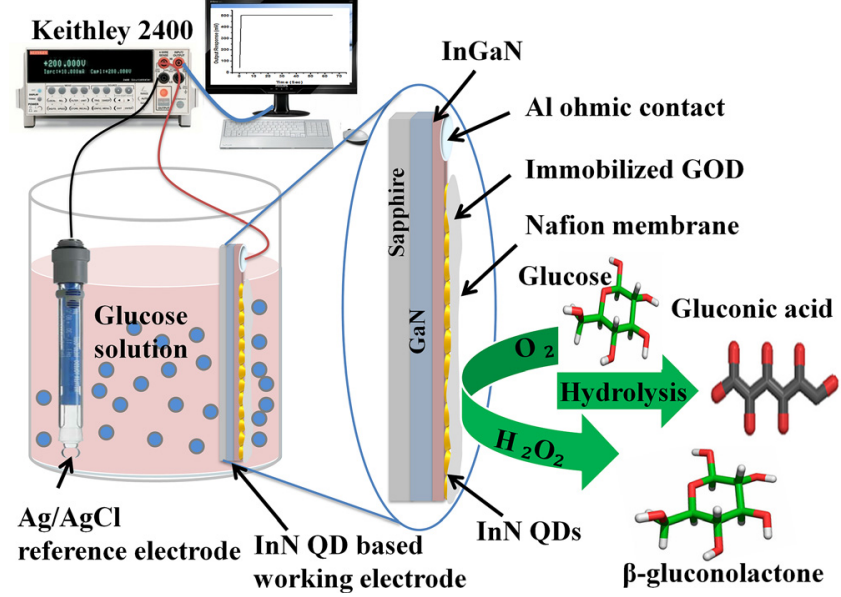

FIG. 2. Schematic illustration of the glucose sensing setup using working electrode comprised of InN QDs coated with GOD against a $\mathrm{Ag} / \mathrm{AgCl}$ reference electrode, along with the possible electrochemical reaction near the electrode.

trode. It also illustrates the electrochemical reaction near the biosensing electrode.

Figure 3 depicts the electrochemical cell voltage (EMF) response of the fabricated biosensor measured for different glucose concentration solutions ranging from $1 \times 10^{-5} \mathrm{M}$ to $1 \times 10^{-2} \mathrm{M}$. The EMF is linear versus the logarithmic concentration of glucose increasing from $410 \mathrm{mV}$ for $10 \mu \mathrm{M}$ to $658 \mathrm{mV}$ for $100 \mathrm{mM}$, and it shows a significantly high slope value of $80 \mathrm{mV} /$ decade. The sensor performance is found to be independent of any influence of sensing area that is dipped into the glucose electrolyte solution and the quantity of the glucose electrolyte solution. Repeated experiments (denoted Exp. \#1-3) with the same biosensor show reproducible results confirming the stability, linearity, and reusability of the fabricated glucose biosensor.

The presented glucose biosensor also delivers fast output voltage (EMF) response as a function of time. A very stable output signal is achieved within $2 \mathrm{~s}$, as shown in Figure 4(a), attributed to the planar arrangement of the InN QDs. The time response of the bare InGaN layer, which also has been measured, is much slower, and the maximum EMF is significantly lower. The output signal is not stable and drops

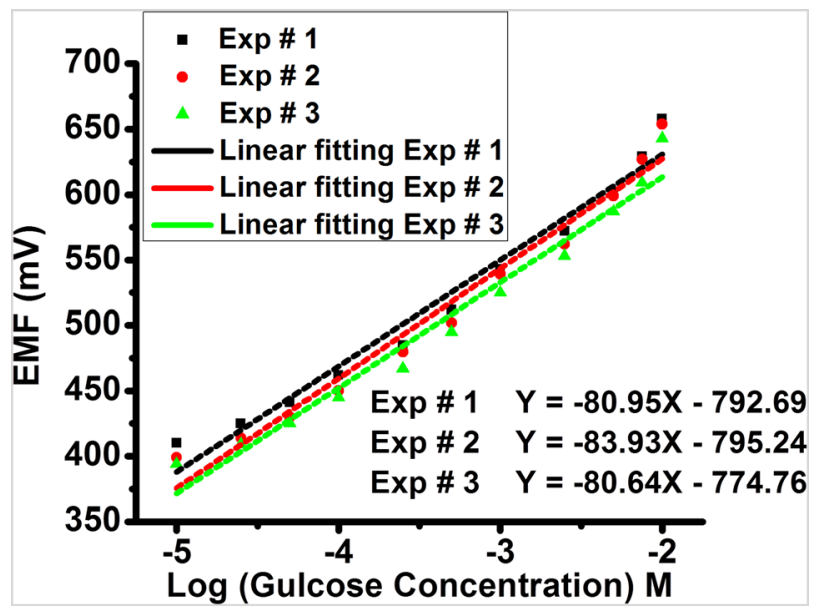

FIG. 3. EMF as a function of the logarithmic glucose concentration ranging from $1 \times 10^{-5}$ to $1 \times 10^{-2} \mathrm{M}$. Exp. \#1-3 denote three different experiments. 


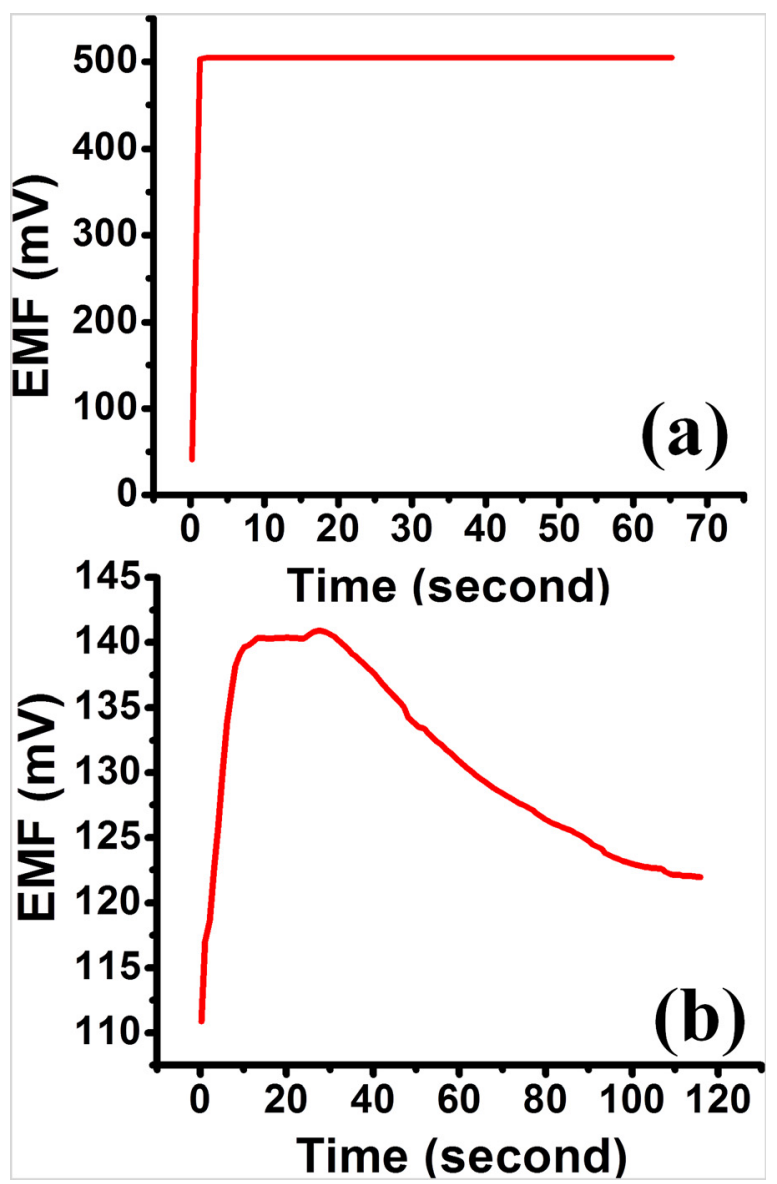

FIG. 4. (a) EMF as a function of time of the InN QDs based potentiometric glucose biosensor for $500 \mu \mathrm{M}$ glucose concentration. (b) EMF as a function of time of the InGaN layer based potentiometric glucose biosensor for $1 \mathrm{mM}$ glucose concentration.

in time, as shown in Figure 4(b). This reveals the major contribution of the InN QDs for precise and stable glucose sensing, attributed to the high surface charge density.

The selectivity of the presented glucose biosensor was also investigated in particular with regard to well known interfering agents such as ascorbic acid and uric acid. Upon the addition of $50 \mu \mathrm{M}$ ascorbic acid or uric acid to $500 \mu \mathrm{M}$ glucose solution the output (EMF) signal does not substantially change, as shown in Figure 5(a). This reveals that the presented biosensor has good selectivity which is attributed to the perm selective (charge-exclusion) property ${ }^{18,19}$ of the Nafion film coated on the sensing electrode.

Moreover, the presented glucose biosensor exhibits excellent storage stability as evidenced by a series of repeated experiments for fourteen consecutive days as shown in Figure 5(b). These measurements were performed to ensure that the biosensor can be used for routine diagnosis retaining its sensitivity and reusability for long durations of time.

Temperature has an effect on the output EMF response of the fabricated glucose biosensor, shown in Figure 6. The output EMF response at a certain glucose concentration increases with increasing temperature up to $40^{\circ} \mathrm{C}$ and then decreases. This reveals that at temperatures below $40^{\circ} \mathrm{C}$ the activity of the enzyme decreases, as well as at temperatures above $40^{\circ} \mathrm{C}$, leading to a decrease of the output EMF. Hence, care needs to

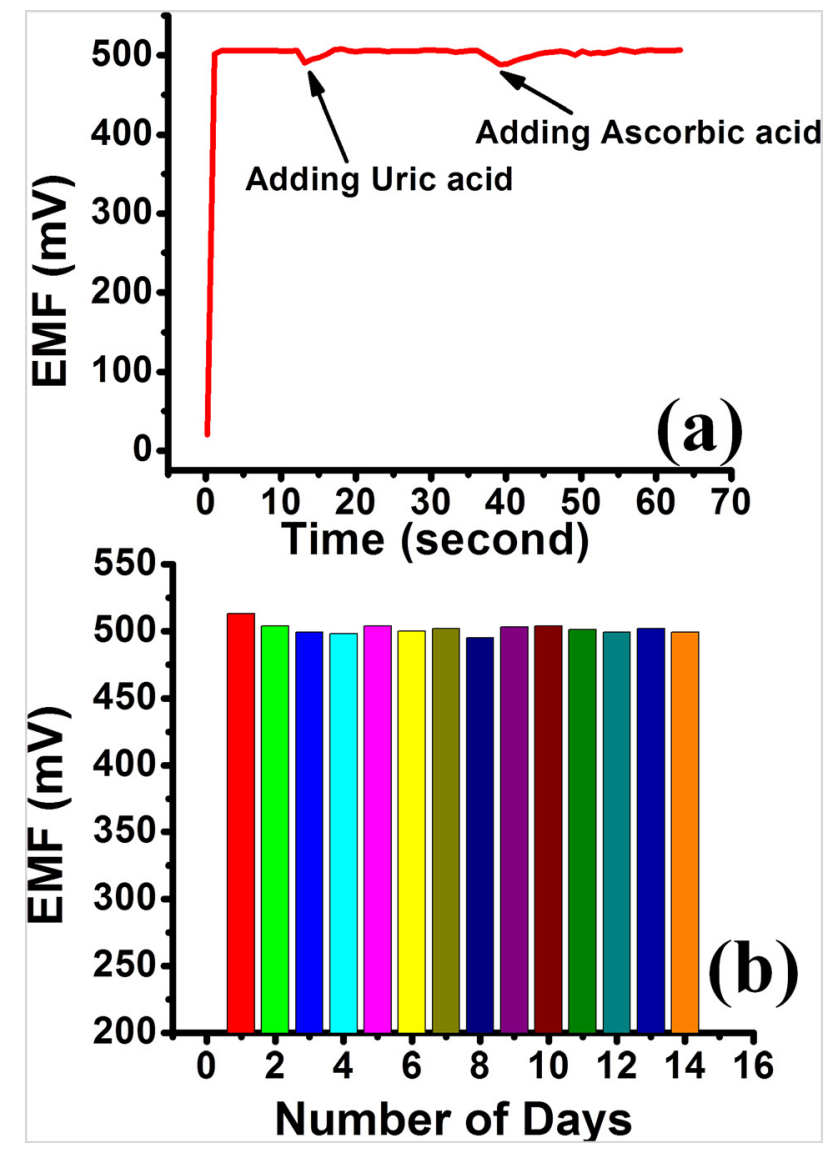

FIG. 5. (a) EMF as a function of time with adding $50 \mu \mathrm{M}$ ascorbic acid (AA) and uric acid (UA) in $500 \mu \mathrm{M}$ glucose solution. (b) Repeated experiments for fourteen consecutive days in $500 \mu \mathrm{M}$ glucose solution using same biosensor.

be taken to control the temperature during glucose sensing measurements, which however is not related to the excellent sensing properties of the InN QDs.

In all, our presented glucose biosensor has high sensitivity, excellent reusability, good selectivity, and rapid response time, withstanding any comparison with other available enzymatic glucose biosensors, as shown in Table I, listing the functional properties of different available enzymatic glucose biosensors developed by using different techniques. ${ }^{20-26}$

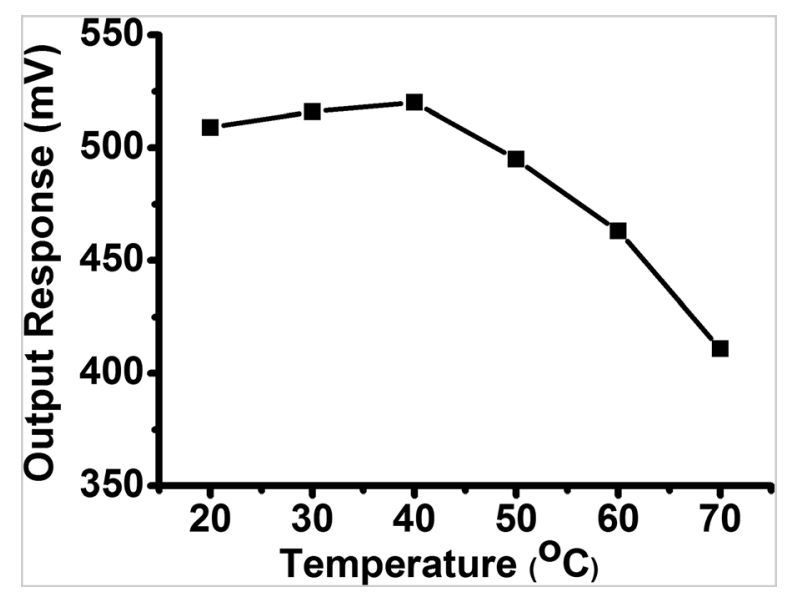

FIG. 6. EMF as a function of temperature of the InN QDs based biosensor in $500 \mu \mathrm{M}$ glucose solution. 
TABLE I. Functional properties of different available enzymatic glucose biosensors.

\begin{tabular}{|c|c|c|c|c|}
\hline Electrode matrix & Detection techniques & Sensitivity/detection limit & Response time(s) & Reference \\
\hline $\mathrm{ZnO}$ nanowires & Amperometric & $26.3 \mu \mathrm{A} \mathrm{mM}^{-1} \mathrm{~cm}^{-2} / 0.7 \mu \mathrm{M}$ & 10 & 20 \\
\hline $\mathrm{ZnO}$ nanotube & Potentiometric & $69.12 \mathrm{mV} /$ decade $/ 0.5 \times 10^{-6} \mathrm{M}$ to $12 \times 10^{-3} \mathrm{M}$ & $\sim 4$ & 21 \\
\hline $\mathrm{Si}-\mathrm{SiO}_{2}-\mathrm{Si}$ & Potentiometric & $12 \mathrm{mV}$ decade ${ }^{-1}$ in humanurine & 90 & 22 \\
\hline $\mathrm{CNT} /$ perfluorosulfonate ionomer- $\mathrm{SiO}_{2}$ nanocomposite & Amperometric & $5.01 \mu \mathrm{A} \mathrm{mM}^{-1} / 0.1 \mu \mathrm{M}$ & $\sim 6$ & 23 \\
\hline $\mathrm{RhO}_{2}$ modified carbon ink & Amperometric & $64 \mu \mathrm{A} \mathrm{mM} M^{-1} \mathrm{~cm}^{-2} / 1.11 \mu \mathrm{M}$ & 28 & 24 \\
\hline $\mathrm{ZnO}$ nanocomb & Amperometric & $15.33 \mu \mathrm{A} \mathrm{mM}^{-1} \mathrm{~cm}^{-2} / 20 \mu \mathrm{M}$ & $<10$ & 25 \\
\hline $\mathrm{SnO}_{2}$ film enzymatic & Potentiometric & $50 \pm 2 \Delta \mathrm{mV} \Delta \mathrm{pC}^{-1 /-}$ & $\sim 300$ & 26 \\
\hline PDDA-SWCNT-GOD & Amperometric & $63.84 \mu \mathrm{A} \mathrm{mM}^{-1} \mathrm{~cm}^{-2} / 4 \mu \mathrm{M}$ & $\ldots$ & 27 \\
\hline MWCNT/PtNP/CS/MTOS/GOD & Amperometric & $69.9 \mu \mathrm{A} \mathrm{mM}^{-1} \mathrm{~cm}^{-2} / 0.4 \mu \mathrm{M}$ & $\ldots$ & 28 \\
\hline
\end{tabular}

To summarize, we fabricated a glucose biosensor based on the combination of glucose oxidase and InN QDs. The presented biosensor utilizes the substantial advantages of high surface charge density and low-dimensionality of the InN QDs for highly sensitive and rapid response. We have investigated the sensitivity, reusability, and selectivity over a large glucose concentration range from $1 \times 10^{-5}$ to $1 \times 10^{-2} \mathrm{M}$. The fabricated glucose biosensor had an excellent sensitivity slope of $80 \mathrm{mV} /$ decade with fast output response of $2 \mathrm{~s}$. The high sensitivity, excellent reusability, good selectivity, and rapid response time reveal that our glucose biosensor is a promising candidate for glucose determination in clinical diagnoses.

R.N. likes to thank the BBVA foundation for financial support.

${ }^{1}$ S. D. Franceschi, L. Kouwenhoven, C. Schönenberger, and W. Wernsdorfer, Nat. Nanotechnol. 5, 703 (2010).

${ }^{2}$ F. Qian, Y. Li, S. Gradečak, H. G. Park, Y. Dong, Y. Ding, Z. L. Wang, and C. M. Lieber, Nat. Mater. 7, 701 (2008).

${ }^{3}$ H. Lu, W. J. Schaff, J. Hwang, H. Wu, G. Koley, and L. F. Eastman, Appl. Phys. Lett. 79, 1489 (2001).

${ }^{4}$ K. Xu and A. Yoshikawa, Appl. Phys. Lett. 83, 251 (2003).

${ }^{5}$ S. Gwo, C. L. Wu, C. H. Shen, W. H. Chang, T. M. Hsu, J. S. Wang, and J. T. Hsu, Appl. Phys. Lett. 84, 3765 (2004).

${ }^{6}$ H. Lu, W. J. Schaff, L. F. Eastman, and C. E. Stutz, Appl. Phys. Lett. 82, 1736 (2003).

${ }^{7}$ K. A. Rickert, A. B. Ellis, F. J. Himpsel, H. Lu, W. Schaff, J. M. Redwing, F. Dwikusuma, and T. F. Kuech, Appl. Phys. Lett. 82, 3254 (2003).

${ }^{8}$ I. Mahboob, T. D. Veal, C. F. McConville, H. Lu, and W. J. Schaff, Phys. Rev. Lett. 92, 036804 (2004).
${ }^{9}$ K. Jeganathan, V. Purushothaman, R. K. Debnath, R. Calarco, and H. Luth, Appl. Phys. Lett. 97, 093104 (2010).

${ }^{10}$ I. Mahboob, T. D. Veal, L. F. J. Piper, C. F. McConville, H. Lu, W. J. Schaff, J. Furthmüller, and F. Bechstedt, Phys. Rev. B 69, 201307 (2004).

${ }^{11}$ Y. S. Lu, C. C. Huang, J. A. Yeha, C. F. Chen, and S. Gwo, Appl. Phys. Lett. 91, 202109 (2007).

${ }^{12}$ N. Sofikiti, N. Chaniotakis, J. Grandal, M. Utrera, M. A. S. García, and E. Calleja, Mater. Lett. 64, 1332 (2010).

${ }^{13}$ C. F. Chen, C. L. Wu, and S. Gwo, Appl. Phys. Lett. 89, 252109 (2006).

${ }^{14}$ H. Lu, W. J. Schaff, and L. F. Eastman, J. Appl. Phys. 96, 3577 (2004).

${ }^{15}$ O. Kryliouk, H. J. Park, H. T. Wang, B. S. Kang, T. J. Anderson, F. Ren, and S. J. Pearton, J. Vac. Sci. Technol. B 23, 1891 (2005).

${ }^{16}$ T. V. A. Dam, D. Pijanowska, W. Olthuis, and P. Bergveld, Analyst 128, 1062 (2003).

${ }^{17}$ D. J. Macaya, M. Nikolou, S. Takamatsu, J. T. Mabeck, R. M. Owens, and G. G. Malliarasa, Sens. Actuators B 123, 374 (2007).

${ }^{18}$ Z. Fan and D. J. Harrison, Anal. Chem. 64, 1304 (1992).

${ }^{19}$ G. Fortier, M. Vaillancourt, and D. Belanger, Electroanalysis 4, 275 (1992).

${ }^{20}$ J. Zang, C. M. Li, X. Cui, J. Wang, X. Sun, H. D. Chang, and Q. Sun, Electroanalysis 19, 1008 (2007).

${ }^{21}$ S. M. U. Ali, M. Kashif, Z. H. Ibupoto, M. Fakhar-e-Alam, U. Hashim, and M. Willander, Micro Nano Lett. 6, 609 (2011).

${ }^{22}$ A. S. Poghossian, Sens. Actuators B 44, 361 (1997).

${ }^{23}$ A. I. Gopalan, K. P. Lee, D. Ragupathy, S. H. Lee, and J. W. Lee, Biomaterials 30, 5999 (2009).

${ }^{24}$ P. Kotzian, P. Brázdilová, S. Řezková, K. Kalcher, and K. Vytřas, Electroanalysis 18, 1499 (2006).

${ }^{25}$ J. X. Wang, X. W. Sun, A. Wei, Y. Lei, X. P. Cai, C. M. Li, and Z. L. Dong, Appl. Phys. Lett. 88, 233106 (2006).

${ }^{26}$ F. Kormos, L. Szira'ki, and I. Tarsiche, Lab. Rob. Autom. 12, 291 (2000).

${ }^{27}$ Y. Wang, X. Wang, B. Wu, Z. Zhao, F. Yin, S. Li, X. Qin, and Q. Chen, Sens. Actuators B 130, 809 (2008).

${ }^{28}$ X. Kang, Z. Mai, X. Zou, P. Cai, and J. Mo, Talanta 74, 879 (2008). 